\title{
Comprehensive Assessment of Functional Changes in the Organism of Healthy Rats in External and Internal Use of Silicone Low-Mineralized Mineral Water
}

\author{
Sergey Gushcha ${ }^{1}$, Boris Nasibullin ${ }^{1}$, Alexander Plakida ${ }^{2}$, , Irina Trubka ${ }^{3}$, Veronika Volyanskaya ${ }^{4}$, \\ Nikolay Kalinichenko ${ }^{4}$, Irina Balashova ${ }^{4}$ \\ ${ }^{1}$ Department of Basic Research, SE Ukrainian Research Institute of Medical Rehabilitation and Balneology Ministry of Health of Ukraine, \\ Odessa, Ukraine \\ ${ }^{2}$ Department of Physical Rehabilitation, Sports Medicine, Physical Training and Valeology, Odessa National Medical University, Odessa, \\ Ukraine \\ ${ }^{3}$ Department of Childhood Stomatology, National Medical Academy of Post-Secondary Education, Kiev, Ukraine \\ ${ }^{4}$ Department of Physical Rehabilitation, SE Ukrainian Research Institute of Medical Rehabilitation and Balneology Ministry of Health of \\ Ukraine, Odessa, Ukraine
}

\section{Email address: \\ aplakida@mail.ru (A. Plakida) \\ ${ }^{*}$ Corresponding author}

\section{To cite this article:}

Sergey Gushcha, Boris Nasibullin, Alexander Plakida, Irina Trubka, Veronika Volyanskaya, Nikolay Kalinichenko, Irina Balashova. Comprehensive Assessment of Functional Changes in the Organism of Healthy Rats in External and Internal Use of Silicone LowMineralized Mineral Water. European Journal of Clinical and Biomedical Sciences. Vol. 4, No. 1, 2018, pp. 1-5. doi: $10.11648 /$ j.ejcbs.20180401.11

Received: October 31, 2017; Accepted: December 28, 2017; Published: January 19, 2018

\begin{abstract}
Therapeutic mineral waters (MW) are nonspecific natural modulators; they correct the state of numerous pathogenetic links in the formation of the pathological process in the organism, which allows obtaining long-term therapeutic effects (especially at the initial stages of pathology development). Positive effect from the use of MW is due to their physical and chemical composition: the presence of macro- and microelements and biologically active compounds (sodium, potassium, magnesium, silicon, boron, iron, hydrogen sulfide). MW can be dangerous, because, acting as stress factors of low intensity; they exhaust (with long-term use) adaptive-compensatory mechanisms of the organism and promote the development of disoriginal states. The purpose of the work was to determine the safety and availability of biological activity of thermal silicon low-mineralized water on the state of the organism of healthy white rats at its internal and external application. The influence of MW on the functional state of the nervous system, kidneys, liver and structural and functional organization of the internal organs of white rats was investigated due to the application of physiological, biochemical, histological and statistical methods of research. The experiment was conducted on white rats of the Wistar line, divided into three groups. I group was control, comparative. Animals of II group received silicon MW internally, and animals of group III in the form of external procedures. It was established that the external application of MW causes a more significant calming effect on the functional state of the central nervous system. The emotional state of rats of the third group contrary - activated. The use of MW in animals of group II causes significant stimulation of urinary and excretory renal function. In both groups, the biliary function of the liver is intensified (reducing the total bilirubin content of the blood due to its fractions - direct and indirect bilirubin) and reduces the activity of oxidative-reducing enzymes in the tissues of the stomach, liver and kidneys. Consequently, the use of silicon MW in animals of the II and III groups does not cause harmful or toxic phenomena. The obtained histological results indicate that the animal's organism is in a state of reduced energy supply, that is, it can be assumed that the MW forms the state of adaptation to the damaging factors. In this case, the external application of MW is not less determined than its traditional internal use.
\end{abstract}

Keywords: Silicon Mineral Water, Biological Activity, White Rats, Functional State 


\section{Introduction}

Silicon waters as a balneological group, for a long time practically fell out of the sphere of spa resort application [1]. Given the new view on the biological role of many micronutrients (which also include silicon and boron), which were previously considered only in terms of health risks or not taken into account as factors necessary for human life, now they should be considered as important factors, which correct the course and intensity of many metabolic processes [2-7]. According to the latest literature data, the presence of biologically active components, compounds and substances (silicon, boron, organic matter, etc.), which are xenobiotics by their nature, when it enters the body in mineral water, causes the development of a general adaptive reaction and an increase in nonspecific resistance [8-15].

Taking into account the above, the aim of the study is to conduct a comparative analysis of the influence of lowmineralized hydrocarbonate calcium-sodium mineral water 4 from the well No. 1-SG near the village Barvynok, Uzhgorod district of the Transcarpathian region (MW) with increased content of metasilic acid and orthoboric acid on the functional state of the nervous system, kidney, liver and structural and functional organization of the internal organs of healthy animals with their internal and external application.

According to the physical and chemical characteristics, these groundwater is classified as thermal silicon mineralized sodium hydrocarbonate, neutral containing metasilic acid at a concentration of $225.97 \mathrm{mg} / \mathrm{l}$ and orthobic acid at concentrations of $33.0-52.0 \mathrm{mg} / 1$.

\section{Methods of Research}

The experiment was carried out on 50 white rats-females of the Wistar line of outbred breeding with a body weight of 180-200 g under expeditionary conditions. The work was carried out in accordance with the rules laid down in the Directive of the European Parliament and of the Council of Europe (2010/63 / EU) [16, 17].

Experimental studies of the influence on the organism of complex natural systems, which are also MW, require the selection of such integral indicators that reflect the state of physiological activity of the basic systems of the organism. These include:

Indices of activity of the central nervous system (CNS), which were evaluated by changes in orienteering and research behavior (ORB), motor activity and level of emotional state of animals (the method of "open field") [18].

Functional state of the kidneys was evaluated according to the state of function of urine formation (glomerular filtration rate, tubular reabsorption, daily diuresis) and excretory function (by excretion of creatinine and urea), ion-regulating function (concentration and daily excretion of sodium ions, potassium, calcium and chloride ions). In addition, the acidalkaline reaction of the daily urine was determined on the basis of the concentration of hydrogen ions.
The functional state of the liver was determined by the activity of the enzymes alanine aminotransferase (AlT), aspartate aminotransferase (AST). Determination of the activity of ALT and AST in serum was carried out by ReitmanFrenkel method (a set of reagents Filisit-diagnostics). The content of the total bilirubin and its fractions in the blood was carried out by diazoreaction in the presence of an accelerator (Yendrashek, Kleghorn, and Grof method). The antioxidant system in the blood was examined in the activity of the enzyme catalase, and the activity of lipid peroxidation (LPO) in the content of malonic dialdehyde (MDA) using thiobarbituric acid in a biological material. The activity of the processes catabolism was determined by the content of creatinine and urea in blood by Popper's method [19, 20, 21].

According to the results of histological studies, changes in the structural and functional organization of the main internal organs (heart, stomach, liver, kidneys) were determined; the histonezymic reactions determined the activity of the leading enzymes of the oxidation-reduction reactions - succinate dehydrogenase (SDG) and lactate dehydrogenase (LDH). Animals were extracted from the experiment by decapitation under the aesthetic anesthetic. The removed organs (stomach, heart, liver, kidneys) were fixed in $4 \%$ of paraformaldehyde solution for $72 \mathrm{~h}$. Then they were carried through spirits of increasing concentration and poured into celloidine. From the obtained blocks, histologic sections 7-9 mkm thick, which were stained with haemotaxylin-eosin, and Van-Gizon were made. Microscopic studies were performed using Zeizz light microscope (Prima Star model). For histochemical studies, the native material was frozen with chlorretil in a cryostat at a temperature of $-18^{\circ} \mathrm{C}$, and cut-offs of $11 \mathrm{mkm}$ were made, in which, according to Lloyd's records, the activity of the leading enzymes of oxidative-reducing reactions-succinate dehydrogenase (SDG) and lactate dehydrogenase (LDH) was determined.

MW introduced into the esophagus by soft probe with metal olive during 7 days, once daily, at a dose of $1 \%$ of body weight in the evening (around 17.00), taking into account circadian biorhythm of rats. In the mode of external application, the way of receipt of MW to the organism of animals - skin-resorptive. Tailings of animals that were in a fixed condition (a special setting) are immersed in a test tube with $2 / 3$ of a length, which is $5 \%$ of the body surface. The temperature of the test substance was maintained at $38-40^{\circ}$ C. The daily exposition lasted 2 hours, the course consisted of 5 procedures, at intervals of 1 day.

Experimental animals were divided into 3 groups.

I group (control), comparative (10 intact animals); II group (20 animals) - healthy animals, who received an intra-course of MW; III group (20 animals) - animals who received an external course of MW.

The methodical techniques and techniques used in the studies correspond to Order of the Ministry of Health of Ukraine "On Approval of Methodological Recommendations on Methods of Research on the Biological Effects of Natural Medicinal Resources and Preformed Therapeutic 
Facilities"[5]. The statistical processing of the data obtained in the series of experiments was carried out by the method of indirect differences, while the reliable shifts were those that were within the limits of probability according to the Student's tables $(p<0,05)$ [22].

\section{Results and Discussion}

Studies have shown that MW in its course of internal application has a small calming effect to the functional state of the central nervous system of healthy rats. The motor activity of animals is reduced by reducing the outputs to the center of the site by $42 \%$ ( $p<0.001)$, increasing the number of stops and their duration by 33 and $65 \%$ respectively ( $p$ $<0.001$ and $\mathrm{p}<0.001$ ), with the fact that the number of crossed squares is not differs from the indicator of the control group ( $\mathrm{p}>0.05)$. When moving animals in the "open field" device, the number of vertical racks decreased by $65 \%$ ( $<0.001$ ) and the number of mating in mink was determined by $27 \%$ (the number of crossed squares does not differ from the control indicators $(p>0.05))$. That is, the ORB of healthy rats is reduced slightly. The emotional activity of the experimental animals under the influence of the internal application of MW is reduced due to a decrease by $23 \%$ (p $<0.001$ ) of the duration of the grooming, indicating some suppression of the emotional state.

Emotional activity of experimental animals under the influence of external use of MW in contrast to the internal one - increases due to an increase of $62 \%$ of the number of acts of grooming and that is important, an increase in the duration of grooming by $67 \%$, which indicates that the animals are in a state of intense waiting. Animals most of the experiment were within one square (concentrated on washing and cleaning of fur), but did not look stagnant or oppressed. At the same time, the number of acts of defecation decreases by $34 \%$, indicating that the animals are not afraid.

Application of the MW in both regimens (internal and external) has the same stimulating effect on the functional state of the kidneys of healthy rats.

The volume of diuretic daily in animals of group II increases by $33 \%$, as at the expense of $60 \%$ acceleration of glomerular filtration rate, and due to insignificant but reliable decrease of tubal reabsorption $(0.08 \%$ at $p<0.001)$. In animals of the III group, the volume of diuretic is increased by $21 \%$ only due to $70 \%$ acceleration of glomerular filtration rate, the size of tubular reabsorption of water in the renal tubules does not change ( $p>0.1)$. The elimination of creatinine and chlorides increases both under the influence of internal and external use of MW for 60 and 30\% in the first case and 70 and $61 \%$ in the second respectively. The $\mathrm{pH}$ of the daily urine does not differ from the data of the control group ( $p>0.2$ and $p>0.5)$. It should be noted that external use of MW causes a more intense effect on the functional state of kidneys of healthy rats.

In conducting research on the metabolic status of rats, it has been established that external and internal application of MW has a unidirectional effect on the metabolic rate of healthy animals that have been studied (Table 1). In rats of group II was established a significant decrease in the activity of enzymes of re-maturation of AlT and AsT $(p<0.01)$, while the Ritis index was not changed ( $p>0,5$, so, the balance of these reactions was maintained. In the third group of rats significantly decreased ALT $(\mathrm{p}<0.01)$ and AST - changed ( $>0.5$ ), and the value of the Ritis index increased significantly $(p<0.05)$, so there is an imbalance. A significant decrease in the content of total bilirubin due to the redistribution of its fractions - direct and indirect bilirubin of blood ( $\mathrm{p}<0.01$ both) in animals of both groups compared with the control data was detected. At the same time, the decrease is more clearly defined in animals of the third group. In rats of group II, the level of creatinine and urea did not change ( $p>0.5$ and $p>0.5)$, in animals receiving intravenous $\mathrm{MW}$, the level of creatinine was slightly increased $(\mathrm{p}<0.01)$ and the urea content remained unchanged $(\mathrm{p}>0.5)$.

Indicators of the LP / AOS system (MDA content and catalase activity) remained at the control level, indicating that the normal level and balance of these organism systems in the experimental animals was maintained.

Table 1. Influence of $M W$ on internal and external use on metabolic indices of rats.

\begin{tabular}{|c|c|c|c|c|c|}
\hline Indexes & $\begin{array}{l}\text { I group (control) } \\
\left(M_{1}^{ \pm} \mathbf{m}_{1}\right)\end{array}$ & $\begin{array}{l}\text { II group (internal } \\
\text { application) }\left(M_{2} \pm m_{2}\right)\end{array}$ & $\mathbf{P}_{1}$ & $\begin{array}{l}\text { IIIgroup (external } \\
\text { application) }\left(M_{3} \pm m_{3}\right)\end{array}$ & $\mathbf{P}_{2}$ \\
\hline AlT, U/l & $113,31 \pm 2,13$ & $70,20 \pm 4,20$ & $<0,01$ & $76,17 \pm 5,01$ & $<0,01$ \\
\hline AsT, U/1 & $289,64 \pm 12,12$ & $186,74 \pm 3,81$ & $<0,01$ & $278,70 \pm 4,54$ & $>0,5$ \\
\hline Richtis Index & $2,56 \pm 0,11$ & $2,71 \pm 0,22$ & $>0,5$ & $3,71 \pm 0,20$ & $<0,05$ \\
\hline \multicolumn{6}{|l|}{ Bilirubin, $\mu \mathrm{mol} / 1$} \\
\hline Total & $8,44 \pm 0,28$ & $4,76 \pm 0,31$ & $<0,01$ & $4,47 \pm 0,23$ & $<0,01$ \\
\hline Direct & $3,06 \pm 0,18$ & $1,94 \pm 0,19$ & $<0,05$ & $1,83 \pm 0,10$ & $<0,01$ \\
\hline Undirect & $5,38 \pm 0,15$ & $2,81 \pm 0,20$ & $<0,01$ & $2,63 \pm 0,15$ & $<0,01$ \\
\hline Creatinin, $\mu \mathrm{mol} / 1$ & $47,80 \pm 0,63$ & $47,93 \pm 1,61$ & $>0,5$ & $49,66 \pm 2,55$ & $>0,5$ \\
\hline Urea, $\mu \mathrm{mol} / 1$ & $2,80 \pm 0,27$ & $3,65 \pm 0,14$ & $<0,05$ & $2,96 \pm 0,06$ & $>0,5$ \\
\hline POL (MDA), nmol/(min'mg) & $5,94 \pm 0,21$ & $6,36 \pm 0,38$ & $>0,5$ & $5,87 \pm 0,27$ & $>0,5$ \\
\hline AOS (Catalase), $\%$ & $76,7 \pm 1,52$ & $70,91 \pm 3,11$ & $>0,5$ & $77,29 \pm 2,88$ & $>0,5$ \\
\hline
\end{tabular}

Note: $\mathrm{P}_{1}$ is the reliability of the difference in the comparison between the 1st and 2 nd groups; $\mathrm{P}_{2}$ is the reliability of the difference in the comparison between the 1 st and 3 rd groups. 
pathological changes in them and some relaxation of oxidative-reducing reactions.

Stomach - submucosa plate is dense, without visual changes. Mucous membranes of the usual tubular form, unchanged. In the outflow ducts, large baculovye cells with mucus. Activity of EDC - $(5,0 \pm 0,16) \mathrm{U}$; activity of LDH - $(5,0 \pm 0,11) \mathrm{U}$.

The liver - the lobular structure of the liver is preserved. Hepatocytes are collected in beams, their cytoplasm is homogeneous, basophilic, with medium sized nuclei. Interstitial spaces are cracked. Blood vessel moderated blood vessels. The activity of the EDG - $(5,0 \pm 0,13 \mathrm{U}$; activity of LDH - $(4,0 \pm 0,4) \mathrm{U}$. The liver - the lobular structure of the liver is preserved. Hepatocytes are collected in beams, their cytoplasm is homogeneous, basophilic, with medium sized nuclei. Interstitial spaces are cracked. Vessels of moderate blood are filling. The activity of the EDG - $(5,0 \pm 0,13) \mathrm{U}$; activity of $\mathrm{LDH}-(4,0 \pm 0,4) \mathrm{U}$.

Heart - layer and beam organization of myocardium without visual changes. Cardiomyocytes are common. The activity of the EDG - $(7,0 \pm 0,11) \mathrm{U}$; activity of LDH - $(6.0 \pm 0.27) \mathrm{U}$.

Kidneys - the structure of the nephron and its components without apparent changes. Activity of EDC - $(6.0 \pm 0.13) \mathrm{U}$; activity of $\mathrm{LDH}-(5,0 \pm 0,19) \mathrm{U}$.

Morphological investigations of target organs of healthy rats, which used MW external found the presence of structural manifestations of changes in the functional activity of some organs.

Stomach - submucosa plate dense, fibroblasts a bit. Glands of the mucous plate have the usual tubular form. Epithelial cells with light-basophilic cytoplasm. Goblet cells are enlarged sharply, they have a lot of mucus. The activity of the EDG - $(6.0 \pm 0.30) \mathrm{U}$; activity of LDH - $(5,0 \pm 0,11) \mathrm{U}$.

The liver - the lobular structure is preserved, hepatocytes are densely packed into beams. Hepatocytes have small darkcolored nuclei. Intercostal spaces are widespread, Kupffer's cells are swollen. Vessels of moderate blood are filling. The activity of the EDG - $(5,0 \pm 0,23) \mathrm{U}$; activity of LDH - $(4,0 \pm 0,11) \mathrm{U}$.

Heart - beam and layer organization of myocardium without visual changes. Cardiomyocytes with elongated cores and lumbar hinged. The activity of the EDG - $(6.0 \pm$ $0.17) \mathrm{U}$; activity of LDH - $(6.0 \pm 0.17) \mathrm{U}$.

Kidneys - the structure of the nephron and its components is unchanged. Activity of EDC - $(6.0 \pm 0.13) \mathrm{U}$; activity of LDH - $(5,0 \pm 0,19) \mathrm{U}$.

Consequently, the external and internal application of MW in healthy rats caused a decrease in the activity of oxidativereducing enzymes in the investigated organs.

\section{Conclusion}

Thus, experimental data obtained in our studies coincide with literary sources, which reported the ability of silicon compounds to influence the metabolism of cell membranes, reduce the activity of sympathetic units and increase the activity of the parasympathetic nervous system [3, 4,]. It has been established that the application of the MW in both regimens leads to significant stimulation of urinary and excretory renal function, reduces the activity of AlT and AST and causes the intensification of bile excretory function of the liver. But external application of MW cause these changes are more definite. In addition, both the internal and external application of MW leads to a decrease in the activity of oxidative-reducing enzymes in tissues of investigated organs in healthy rats.

It should be emphasized that the established fluctuations of the metabolism indices in healthy animals under the influence of MW with its internal and external application did not go beyond the limits of physiological norms and did not cause harmful or toxic phenomena.

As a whole, it can be argued that the external application of MW has a no less definite effect on the functional state of the organism's system of rats than its traditional internal use. The obtained data allowed to determine the choice of experimental pathologies (carbohydrate metabolism disturbances, stress-induced pathological conditions) and substantiated studies to determine the presence of therapeutic properties (or corrective actions) of this MW in the abovementioned pathologies.

\section{References}

[1] Mineral waters of Ukraine / Ed. By E. O. Kolesnik, K. D. Baбov.-K.: Kupriyanov, 2005, 576 p.

[2] Medical-hydrogeochemical factors of geological environment in Ukraine/ Ed. By H. I. Rud'ko. Kyiv-Chernivtsi: Bukrek, $2015,724 \mathrm{p}$.

[3] Nasibullin B. A., Gushcha S. G. Modern ideas about the biological role of silicon in organism of humans and animals//Medical Rehabilitation, Balneology, Physiotherapy.2006. No. 1 (45), P. 29-32.

[4] Experimental evaluation of the effect on the organism of the low-mineralized sodium chloride mineral water of the Ketkinsky deposit and the mud extract from the Paratunskoye field / С. В. Калинин // Questions of balneology, physiotherapy and medical physical training.-2002.—№ 6.-P. 35-37.

[5] Kim M. H. Silicon supplementation improves the bone mineral density of calcium-dcficicnt ovaricctomized rats by reducing bone resorption / M. H. Kim, Y. J. Bae, M. X. Choi // Biol Trace F. lcm Res. 2009. Vol. I28 (3). P. 239-247.

[6] A. P. Avcyn, A. A. Zhavoronkov, M. A. Risch, L. S. Strochkova. Microelementoses of man: etiology, classification, organopathology.-M.: Medicina, 1991.—496 p.

[7] T. A. Zolotareva, B. A. Nasibullin, S. G. Gushcha, N. A. Alexeenko, E. I. Bakholdina, A. Ya. Oleschko. Influence of boric mineral medicinal-table water on the functional state of the liver of experimental animals with chronic alcoholization // Physiotherapy, balneology and rehabilitation.-2014.-№ 1.-P. 4-7.

[8] Pavlova E. S., Bakholdina E. I., Batsko E. S. Influence of mineral waters of various macro-composition and the content of biologically active substances on nonspecific mechanisms of formation of adaptive processors//Medical Rehabilitation, Balneology, Physiotherapy.- 2008, No. 3, P. 19-22. 
[9] Tolmacheva N. V. On the role of auto-microflora and microelements in the formation of ecological-physiological features of adaptation.// The success of modern natural science. 2003, No. 5, P. 89-90.

[10] Soetan K. O., Olaiya C. O., Oyewole O. E. The importance of mineral elements for humans, domestic animals and plants: A // African Journal of Food Science. 2010. Vol. 4 (5). P. 200222.

[11] Jugdaohsingh R., Simon H. C., Anderson, K. L. Dietary silicon intake and absorption / American Journal Clinical Nutrition. 2002. Vol. 75 (5). P. 887-893.

[12] A. V. Scalny. Mikroelementozy of human: diagnosis and treatment. 2 nd ed. - M.: KMK,-2001.—96 p.

[13] Nzietchueng R. M., Dousset B., Frank P. Mechanisms implicated in the effects of boron on wound healing / Journal Trace Elements Medical Biology. 2002. Vol. 16 (4). P. 239244.

[14] Davenwarda S., Benthamb P., Wrightb J. Silicon-rich mineral water as a non-invasive test of the "aluminum hypothesis' in alzheimer's disease // Journal of Alzheimer's Disease. 2013. Vol. 33. P. 423-430.

[15] Rehabilitation of victims in conditions of emergencies and hostilities. Post-traumatic stress disorder/Ed. К. Д. Babov, I. Ya. Pinchuk, V. V. Steblyuk.-Odessa, «Polygraph», 2015$240 \mathrm{p}$.

[16] Directive 2010/63/ EU of the European Parliament and of the
Council of 22 September 2010 on the protection of animals used for scientific purposes (Text with EEA relevance). Official Journal. 2010, L. 276, pp. 0033-0079.

[17] Kozhemyakin Yu. N., Khromov OS., Boldyreva NE., Dobrelya NV., Sayfetdinova GA. Scientific and practical recommendations for the maintenance of laboratory animals and work with them: monograph.- K.: Interservice. 2017: $182 \mathrm{p}$.

[18] Celis M. E. Measurement of Grooming Behaviour / M. E. Celis, E. Torre/In: Methods in Neurosciences, New York: Academic Press. - 1993. P. 359-378.

[19] Aleksyeyenko N. O., Pavlova O. S., Nasibullin B. A., Ruchkina A. S. Manual methods of research and preformed natural treatment means: natural mineral therapeutic table water and therapeutic water, drinks based on them; artificially mineralized water; peloids, brines, clay, waxes and preparations based thereon. Part 3. Experimental and clinical researches]. Odesa, 2002, $120 \mathrm{p}$.

[20] Goryachkovsky AM. Clinical biochemistry in laboratory diagnostics. - ed. 3rd. - Odessa: Ecology. 2005-459p.

[21] Order of MH of Ukraine No. 692 from 28.09.2009. «On approval of the methodological recommendations on research methods of biological effects of natural medicinal resources and preformed medicines.

[22] Glants S. Biomedical Statistics / Trans. English.-M.: Praktika. 1999: 459 p. 